\title{
Management in congenital nasolacrimal duct obstruction - guidelines of the Polish Ophthalmological Society*
}

\section{Beata Urban', Agnieszka Samsel², Erita Violetta Filipek ${ }^{3}$, Anna Maria Niwald ${ }^{4}$, Patrycja Krzyżanowska-Berkowska ${ }^{5}$, Alina Bakunowicz-tazarczyk ${ }^{1}$}

'Department of Pediatric Ophthalmology with Strabismus Treatment Centre, Medical University of Bialystok, Bialystok, Poland ${ }^{2}$ Children's Jan Bogdanowicz Hospital, Warsaw, Poland

${ }^{3}$ Teaching Department of Pediatric Ophthalmology in the Chair of Ophthalmology, Medical University of Silesia, Katowice, Poland ${ }^{4}$ Central Teaching Hospital of the Medical University of Lodz, Lodz Poland

${ }^{5}$ Department of Ophthalmology, Wroclaw Medical University, Wroclaw, Poland

\section{ABSTRACT}

Authors present the etiology, clinical presentation, diagnosis, and management of congenital nasolacrimal duct obstruction (CNLDO). The problem of immediate and deferred probing for CNLDO is dis- cussed. The paper presents also guidelines of the Polish Ophthalmological Society in CNLDO management.

KEY WORDS: congenital nasolacrimal duct obstruction, management, guidelines.

\section{CONGENITAL NASOLACRIMAL DUCT OBSTRUCTION - CAUSES, SYMPTOMS}

Congenital nasolacrimal duct obstruction (CNLDO) is the most common cause of persistent lacrimation with secretion in the eye, in children. Symptoms appear in approx. $5 \%$ of neonates and infants. Most often it is caused by presence of an abnormal membrane in the distal segment of the nasolacrimal duct (Hasner's valve), hence usually we are dealing with congenital obstruction of the nasolacrimal duct. Much less often, difficulties in the outflow of tears in children is caused by stenosis of the nasolacrimal duct or, for example, absence of lacrimal points and ducts. An increased risk of tear duct obstruction occurs in children with Down syndrome, hemifacial hypoplasia, midfacial anomalies, craniosynostoses, Goldenhar syndrome, and cleft syndromes.

Obstruction of the lacrimal duct and the associated blockage in the outflow of tears causes several symptoms, includ- ing retention of tears, wet and clustered eyelashes, presence of secretion in the conjunctival sac (initially mucous, then mucopurulent or purulent) accumulating on the edges of eyelids and on eyelashes, and retention of pathological content in the lacrimal sac. Those symptoms develop in the first month of life. In $30 \%$ of children with congenital nasolacrimal duct obstruction, problems with outflow of tears occur bilaterally. In these cases, complex obstruction in the upper part of the nasolacrimal ducts (lacrimal ducts, lacrimal sac, upper part of the nasolacrimal duct) is more common, rather than obstruction at Hasner's valve level.

Main complications of CNLDO are: dacryocystitis, inflammation of orbital soft tissue, upper respiratory tract infection, more frequent anisometropia and amblyopia on the side of obstructed lacrimal ducts.

The diagnosis of CNLDO is based mostly on characteristic clinical symptoms. In case of doubts, the fluorescein appear-

\footnotetext{
${ }^{*}$ Guidelines of scientific societies and associations (including the Polish Ophthalmological Society) do not constitute binding laws and do not determine the only correct procedures; they are only an opinion of a group of experts from a given field. The opinion reflects the current state of knowledge based on available scientific research results.

The guidelines do not exempt healthcare workers from personal liability with regard to making the correct decisions for individual patients.

Personal responsibility for the used therapeutic methods rests with all individuals who practise medicine. It should be based on thorough knowledge and practical skills, while observing necessary safety measures with regard to oneself and the patient.

Readers of this paper are obliged to make themselves familiar with current information on the presented treatments and pharmacotherapies with special attention paid to manufacturers' information on doses, time, and administration as well as side effects of the used drugs.

The publishers and editors of the paper shall not be responsible for any damages that could in any way be connected to the contents of this paper.
} 
ance test can be done or radiographic imaging applied (computed tomography, magnetic resonance imaging, dacryocystography, scintigraphy of lacrimal ducts). Dacryoendoscopy is also performed lately (also in children, with a favorable success rate), consisting in introduction of a miniature endoscope, $0.9 \mathrm{~mm}$ in diameter, into the lacrimal duct to look for the site obstructing outflow of tears. In some cases, it is possible to pierce the abnormal membrane in the distal section of the nasolacrimal duct with the endoscope [1].

The differential diagnosis should also consider the following abnormalities: congenital glaucoma, chronic conjunctivitis, foreign body in the conjunctiva/cornea, incorrect eyelid positioning, eyelash tucking, lacrimal point agenesis, corneal erosion, congenital cyst of the lacrimal sac, presence of foreign body in the nasolacrimal duct [2].

\section{THE CLINICAL COURSE OF CONGENITAL NASOLACRIMAL DUCT OBSTRUCTION}

Numerous data from the literature show that $70-90 \%$ of CNLDO cases disappear spontaneously during the 1st year of life $[3,4]$. The possibility of spontaneous restoration of patency of lacrimal ducts significantly decreases after the child is 12 months old, and amounts to only a few to a dozen or so percent [4]. This was confirmed by the analysis of patients with CNLDO who were supervised by their GP in the USA [5]. Among children referred for the procedure of duct patency restoration after the age of 1 , only $4.4 \%$ experienced spontaneous cure.

\section{THE COURSE OF ACTION IN CONGENITAL NASOLACRIMAL DUCT OBSTRUCTION}

\section{Conservative treatment}

Conservative treatment is the first step. Crigler's hydrostatic massage of the lacrimal sac is the first-line procedure. Compression in the projection of the lacrimal sac causes rise of hydrostatic pressure in the nasolacrimal duct, and tearing the membrane in its distal section down. In majority of cases this procedure is sufficient, considering a high ratio of spontaneous resolution of the problem. Parents should perform the massage 3-6 times a day. Antibiotic drops (mainly fluoroquinolone derivatives) are also used, but only in the case of associated conjunctivitis or a very large amount of purulent discharge in the conjunctival sac. In CNLDO, the conjunctival bacterial flora is almost identical to that of healthy children, therefore frequent administration of antibiotics may cause replacement of the normal bacterial flora with antibiotic-resistant flora (the child will be its carrier). In addition, it is worth remembering that antibiotic drops disturb the surface of the eye. Hygiene of eyelashes and eyelids is also important.

\section{Intubation of lacrimal ducts}

If conservative treatment proves unsuccessful, lacrimal ducts should be probed [6]. The risk of inadvertent damage of the duct during the procedure suggests that the procedure should be performed through the upper duct.

The lacrimal sac inflammation and a congenital lacrimal sac cyst (especially bilateral), seen in $0.1 \%$ of patients with CNLDO, are indications for early probing. Earlier surgery may be considered at the request of parents and to prevent eye surface disorders.

Some clinical trials show that the child's age at the time of the first lacrimal duct probing has no effect on the effectiveness of the procedure $[7,8]$. However, the vast majority of reports confirm that the effectiveness of first intubation decreases with the child's age. It is over $90 \%$ in children several months old and is 2-3 times lower in children over 1.5 years of age [9-11]. Therefore, the first probing is more often ineffective in older children. Lower probing efficacy in older children may be due to: 1) inflammation and stenosis in the obstructed lacrimal duct prolonged with the child's age; 2) development of complex obstruction over time (simple obstruction usually resolves spontaneously) [12]. Unfortunately, the effectiveness of re-probing is much lower (50\% on average) $[13,14]$. Reasons for lack of effect observed in re-probing are, among others: 1) creation of a false duct, 2) iatrogenic stenosis of lacrimal ducts following ineffective probing (caused by development of the scar tissue after injury of epithelium of lacrimal ducts) observed in as much as $44 \%$ of cases, 3 ) bleeding during the first probing (may indicate injury of lacrimal ducts) - occurring in $20 \%$ of probing procedures $[15,16]$.

\section{When should intubation of lacrimal ducts be performed?}

This question is the subject of numerous discussions. So far, the optimal timing of the probing procedure, accepted by ophthalmologists all over the world, has not been established.

Some ophthalmologists are in favor of early surgery, i.e. up to 6-8 months of age. In these cases, the lacrimal duct probing procedure is performed under local or general anesthesia. In many countries the procedure is performed in outpatient setting. Advantages of early lacrimal duct sampling are: fewer number of visits (to the GP, pediatrician, ophthalmologist), lower costs, fewer antibiotics, early resolution of the problem, and shortening of the period of adverse symptoms, less risk of infection and transition of inflammation into the chronic process with scarring of lacrimal ducts. In addition, early probing is favored because of psychological aspect associated with parents' mental exhaustion and stress of a child, who tries to avoid onerous massage and eyelid cleaning. Thus, both clinical data and economic analysis speak for early lacrimal duct probing. When making the decision on early probing under local anesthesia, the possibility of aspiration and laryngospasm, as well as discomfort for both the child and the surgeon have to be taken into account. Although lacrimal duct probing is usually a safe procedure, complications do occur, and the risk of them increases with local anesthesia, e.g. creating a false duct in soft tissues, piercing with the probe into the maxillary sinus or through the palate into the oral cavity, epitaxis or bleeding into the conjunctival sac (serious in $1-2 \%$ of cases). Early probing is recommended in countries where access to an ophthalmologist is difficult, and when there is a high risk of the child being lost to follow-up.

Ophthalmologists opting for late probing, over 12 months of age, recommend refraining from lacrimal duct probing until the child is at least 1 year old. In their opinion, there is good chance 
of spontaneous recovery (avoiding costly surgery in children who would heal spontaneously in $70-90 \%$ of cases). Significant disadvantages of late probing are: the need for general anesthesia, the possibility of drug resistance and eye surface disorders resulting from long-term use of antibiotics, higher costs, greater risk of failure ( $>24$ months of age failure of the procedure in $1 / 3$ of CNLDO cases), and much higher cost of the procedure. One of the Pediatric Eye Disease Investigator Group studies in the USA compared the cost of treating children with CNLDO aged 6-9 months, who had immediate probing done in the doctor's office (\$562), with the cost of treating children who had received conservative treatment and deferred probing (\$701) [17]. The conclusion was obvious - immediate probing was more cost-effective. On the other hand, Le Garrec et al. from France analyzed the group of children aged 2-11 months (mean age: 7 months) with CNLDO, comparing costs of probing under local anesthesia during the first visit with deferred probing in children under the age of 5 months [18]. The authors concluded that immediate probing in the doctor's office was the most cost-effective option for children aged 5-12 months. The cost of strategies of waiting for spontaneous healing was 1.56 times higher compared to the cost of immediate probing of lacrimal ducts. Similar results were reported by Petris and Liu [19]. Based on the analysis of numerous databases (including PubMed from 1948-2016) regarding CNLDO, the authors found out that the average cost of immediate probing was lower than the cost of deferred procedure. Additionally, deferring the probing procedure promotes complications associated with chronic inflammation, causing additional adhesions and stenosis of lacrimal ducts, resulting over time in formation of complex obstruction. Probing over the age of 12 months is more often ineffective, and the re-probing efficiency is as low as about $50 \%$.

What is the course of action taken by ophthalmologists in the world in case of congenital nasolacrimal duct obstruction? Ophthalmologists in Canada, Great Britain and Latin American countries recommend lacrimal duct probing for children with CNLDO only after they are 1 year old [20,21]. However, there is a lack of consensus among pediatric ophthalmologists in the US. Although most of them recommend lacrimal duct probing at $>1$ year of age, but the 2018 study of a group of nearly 2,000 children with CNLDO showed that the procedure was most effective when it was performed between 9 and 15 months of age [3]. Ophthalmologists from countries such as Taiwan, France, Germany, Iran, and Japan are divided in their opinions - some are in favor of early probing under local anesthesia in the doctor's office, some are in favor of late probing performed under anesthesia in in-patient setting [22-24]. Clinical studies from numerous centers in Poland show that both early and late probing are carried out in hospital setting, and all confirm that the optimal age of a child during the first lacrimal duct probing procedure is about 6 months [25-28].

\section{RECOMMENDATIONS OF THE POLISH OPHTHALMOLOGICAL SOCIETY (PTO) PREPARED BY EXPERTS OF THE CHILDREN'S OPHTHALMOLOGY AND STRABOLOGY SECTION OF THE PTO REGARDING MANAGEMENT OF CONGENITAL NASOLACRIMAL DUCT OBSTRUCTION}

1. Congenital lacrimal sac cyst

- after ENT examination and confirmation of diagnosis

- requires ENT surgery at the age of about 1 month (considering necessary general anesthesia). In the presence of dacryocystitis, a general and local antibiotic treatment should be used as per the culture antibiogram, and cyst excision should be performed after achieving control over the local inflammation.

2. Obstruction of nasolacrimal ducts:

- conservative treatment in the form of massage of the lacrimal sac until the age of 4-5 months, hygiene of eyelids (cleaning edges of eyelids with tissue paper, rinsing eyelids and the conjunctival sac with $0.9 \% \mathrm{NaCl}$ );

- in the case of recurrent purulent inflammation associated with the presence of purulent secretion in the conjunctival sac, evacuation of purulent secretions during massage of the lacrimal sac, and the need for topical antibiotics, nasolacrimal ducts should be probed at the age of over 5 months.

3. Probing of nasolacrimal ducts:

- early - before the age of 6 months in case of a mucous cyst, abscess of the lacrimal sac, and significant ectasia of the sac with a chronic purulent inflammation persisting despite a correct conservative treatment;

- over the age of 6 months - in case of frequent, recurrent infective inflammations;

- late - between the age of 8 and 12 months, in case of nasolacrimal ducts obstruction with no recurrent infections.

4. Stenosis of nasolacrimal ducts on the level of lacrimal ducts - intubation with silicone tubes, regardless the patient's age.

5. Procedure in case of persistent/recurrent symptoms after a previous probing procedure: re-probing after 4-6 weeks.

6. In case of no improvement after repeated probing procedure, imaging diagnostics and ENT consultation are necessary and management depending on the pathology found:

- stenosis of the nasolacrimal duct and persistence of symptoms despite treatment as above - tear duct intubation;

- obstruction of the nasolacrimal duct - dacryocystorhinostomy (DCR).

The final decision about the applied procedure is made by the attending physician who supervises the patient.

\section{DISCLOSURE}

The authors declare no conflict of interest. 


\section{References}

1. Heichel J, Bachner F, Schmidt-Pokrzywniak A, et al. Treatment of congenital lacrimal duct obstruction: A prospective clinical cohort study. Ophthalmologe 2015; 112: 840-847.

2. MacEwen CJ, Young JD. Epiphora during the first year of life. Eye 1991; 5 (Pt 5): 596-600.

3. Sathiamoorthi S, Frank RD, Mohney BG. Spontaneous resolution and timing of intervention in congenital nasolacrimal duct obstruction. JAMA Ophthalmol 2018; 136: 1281-1286.

4. Kakizaki H, Takahashi Y, Kinoshita S, et al. The rate of symptomatic improvement of congenital nasolacrimal duct obstruction in Japanese infants treated with conservative management during the 1st year of age. Clin Ophthalmol 2008; 2: 291-294.

5. Anhalt J, Liu GT, Weiss SJ, et al. Rate of spontaneous resolution of congenital nasolacrimal duct obstruction prior to scheduled probing in children older than 1 year. J Pediatr Ophthalmol Strabismus 2019; 56: e31-e33.

6. Vagge A, Ferro Desideri L, Nucci P, et al. Congenital nasolacrimal duct obstruction (CNLD0): a review. Diseases 2018; 6: pii: E96.

7. Pediatric Eye Disease Investigator Group: Primary treatment of nasolacrimal duct obstruction with probing in children younger than 4 years. Ophthalmology 2008; 115: 577-584.

8. Beato J, Mota Á, Gonçalves N, et al. Factors predictive of success in probing for congenital nasolacrimal duct obstruction. J Pediatr Ophthalmol Strabismus 2017; 54: 123-127.

9. Kashkouli MB, Beigi B, Parvaresh MM, et al. Late and very late initial probing for congenital nasolacrimal duct obstruction: what is the cause of failure? Br J Ophthalmol 2003; 87: 1151-1153.

10. Katowitz JA, Welsh MG. Timing of initial probing and irrigation in congenital nasolacrimal duct obstruction. Ophthalmology 1987; 94: 698-705.

11. Medghalchi A, Mohammadi MJ, Soltani Moghadam R, Dalili H. Results of nasolacrimal duct probing in children between 9-48 months. Acta Med Iran 2014; 52: 545-551.

12. Honavar SG, Prakash VE, Rao GN, et al. Outcome of probing for congenital nasolacrimal duct obstruction in older children. Am J Ophthalmol 2000; 130: 42-48.

13. Pediatric Eye Disease Investigator Group. Repeat probing for treatment of persistent nasolacrimal duct obstruction. J AAPOS 2009; 13: 306-307.

14. Stager D, Baker JD, Frey T, et al. Office probing of congenital nasolacrimal duct obstruction. Ophthalmic Surgery 1992; 23: 482-484.

15. Lyon DB, Dortzbach RK, Lemke BN, Gonnering RS. Canalicular stenosis following probing for congenital nasolacrimal duct obstruction. Ophthalmic Surg 1991; 22: 228-232.

16. Youn JDH, MacEwen CJ, Ogston SA. Congenital nasolacrimal ductobstruction in the second year of life, a multicentre trial of management. Eye 1996; 10: 484-491.

17. Pediatric Eye Disease Investigator Group. A randomized trial comparing the cost-effectiveness of 2 approaches for treating unilateral nasolacrimal duct obstruction. Arch Ophthalmol 2012; 130: 1525-1533.

18. Le Garrec J, Abadie-Koebele C, Parienti JJ, et al. Nasolacrimal duct office probing in children under the age of 12 months: Cure rate and cost evaluation. J Fr Ophtalmol 2016; 39: 171-177.

19. Petris C, Liu D. Probing for congenital nasolacrimal duct obstruction. Cochrane Database Syst Rev 2017; 7: CD011109.

20. Schellini SA, Ariki CT, Sousa RL, et al. Management of congenital nasolacrimal duct obstruction--latin american study. Ophthalmic Plast Reconstr Surg 2013; 29: 389-392.

21. Puvanachandra N, Trikha S, MacEwen CJ, et al. A national survey of the management of congenital nasolacrimal duct obstruction in the United Kingdom. J Pediatr Ophthalmol Strabismus 2010; 47: 76-80.

22. Heichel J, Struck HG. Minimally invasive diagnostics and therapy of congenital nasolacrimal duct obstruction. Ophthalmologe 2017; 114: 397-408.

23. Rajabi MT, Abrishami Y, Hosseini SS, et al. Success rate of late primary probing in congenital nasolacrimal duct obstruction. J Pediatr Ophthalmol Strabismus 2014; 51: 360-362.

24. Hayashi K, Katori N, Komatsu H, Ohno-Matsui K. Spontaneous resolving rate of congenital nasolacrimal duct obstruction and success rate of late probing after age 18 months: historical cohort study. Nippon Ganka Gakkai Zasshi 2014; 118: 91-97.

25. Lipiec E, Grałek M, Niwald A. Ocena leczenia wrodzonej niedrożności dróg łzowych w materiale własnym. Klin 0czna 2006; 108: 174-177.

26. Wójcik-Niklewska B, Wilczyński T, Filipek E, et al. Leczenie wrodzonej niedrożności dróg łzowych u dzieci. Okulistyka 2012; 4: 45-47.

27. Mrugacz M, Sielicka D, Bakunowicz-Łazarczyk A. Leczenie niedrożności dróg łzowych za pomocą sondowania dróg łzowych u dzieci w wieku poniżej 4 lat. Klin 0czna 2010; 112: 221-222.

28. Wróblewska E, Ciechan J, Gerkowicz M, Flis B. Wrodzona niedrożność dróg łzowych - ocena wyników leczenia. Post Nenatol 2002; 81-82. 